Talía. Revista de estudios teatrales

ISSN-e 2659-806X

\title{
Arquetipos e intertextualidad en la versión teatral italiana de Caperucita en Manhattan, de Carmen Martín Gaite
}

\author{
Nuria Pérez Vicente* \\ Recibido: 4 de febrero de 2020 / Aceptado: 30 de junio de 2020
}

Resumen: Caperucita en Manhattan (1990) es una de las más importantes incursiones de Carmen Martín Gaite en la LIJ. En este artículo nos ocuparemos de la versión teatral italiana, estrenada en 1999 por el Teatro delle Marionette di Gianni e Cosetta Colla, de Milán. Estudiaremos el texto escénico para ver cómo se subvierten los arquetipos tradicionales y el importante papel que cumple en tal proceso la intertextualidad, centrándonos en los rasgos estructurales y lingüísticos que definen a los principales personajes de la novela para observar si permanecen, y cómo, en la versión teatral.

Palabras clave: Carmen Martín Gaite; Caperucita en Manhattan; subversión; arquetipos; intertextualidad.

\section{[en] Archetypes and Intertextuality in the Italian Theatrical Version of Caperucita en Manhattan, by Carmen Martín Gaite}

\begin{abstract}
In this article we propose to study the Italian theatrical version of Caperucita en Manhattan, by Carmen Martín Gaite, premiered in 1999 by the Teatro delle Marionette di Gianni e Cosetta Colla, in Milan. We will study the scenic text to see how traditional archetypes are subverted and the important role that intertextuality plays in this process, focusing on the structural and linguistic features that define the main characters of the novel to observe how they pass, and if they pass, to the theatrical version.
\end{abstract}

Keywords: Carmen Martín Gaite; Caperucita en Manhattan; subversion; archetypes; intertextuality.

Cómo citar: Pérez Vicente, N. (2020). Arquetipos e intertextualidad en la versión teatral italiana de Caperucita en Manhattan, de Carmen Martín Gaite, en Talía. Revista de estudios teatrales, 2, 55-63.

En uno de sus viajes a Nueva York, una Carmen Martín Gaite que siente haber perdido la brújula tras una dolorosa experiencia personal (la muerte de su hija en 1985), crea un personaje que, extraviado como ella, sabrá encontrarse a sí mismo a través de la libertad y de la fuerza de la fantasía ${ }^{1}$. Así nace la que será una de sus más importantes incursiones en la LIJ: Caperucita en Manhattan.

La obra se publica en 1990. La traduccción italiana de 1993 para La Tartaruga tiene efectos inmediatos, y logra desplazar hacia el centro del polisistema literario a una autora situada hasta entonces, en Italia, en una posición muy periférica [Calvi 1998, 1999]. Hasta el 2000 se traducen otras seis novelas que le abren las puertas en este país ${ }^{2}$. La reedición de 1999 y la presentación ese mismo año en la Feria del Libro Infantil de Bolonia promueven una versión teatral de la novela realizada por el Teatro delle Marionette di Gianni e Cosetta Colla, de Milán, estrenada el 9 de abril de 1999, que permanecerá en escena un mes. En este artículo nos proponemos estudiar dicha versión teatral, que es inédita pero hemos podido consultar en los fondos del archivo de la compa-

* Universidad de Macerata

Email: nuria.perezvicente@unimc.it

1 La idea nace a partir de un diseño del ilustrador Juan Carlos Eguillor, y de hecho es a él a quien se dedica la novela: "Para Juan Carlos Eguillor. Por la respiración boca a boca que nos insufló a Caperucita y a mí, perdidas en Manhattan a finales de aquel verano horrible". Lo que muy al principio fue una historia escrita a cuatro manos pasó en seguida a ser obra exclusiva de Gaite, quien refleja en ella su propio desnortamiento: "Ahora soy yo la que tengo que orientarme en este bosque [...]. Caperucita Roja soy más bien yo y ando atenta a la aparición fugaz de los lobos [...]” [Martín Gaite 2002b: 618].

2 Nuvolosità variabile (Firenze, Giunti, 1995); La stanza dei giochi (Milano, La Tartaruga, 1995); La regina delle nevi (Firenze, Giunti, 1996); Lo strano è vivere (Firenze: Giunti, 1998); La torta del diavolo (Milano, Mondadori, 1999); Via da casa (Firenze, Giunti, 2000). Todas ellas en traducción de Michela Finassi Parolo. Hasta entonces solo se habían traducido dos cuentos: La conciencia tranquila, en A. Repetto (ed.), Narratori spagnoli. La nueva ola (Milano, Bompiani, 1962); y Tarde de tedio, en Storie spagnole (Roma, Millelire, 1993). 
ñía, y que Stefania Colla realiza contando con el asesoramiento de la traductora de la novela, Michela Finassi Parolo.

El hecho de que un autor moderno retome un clásico de la LIJ como Caperucita para construir su obra es algo muy frecuente. Sin perder de vista que intertextualidad y plurisignificación son intrínsecos a la literatura posmoderna, el motivo quizá esté también en que los cuentos, que carecen de un prototexto único [Calceglia 2019], son por excelencia polisémicos, articulados y descomponibles, constitutivamente abiertos a la colaboración activa del lector -en consonancia con lo afirmado por la Estética de la Recepción, anticipado en conceptos como el de polifonía, de Bajtín-, a sus interpretaciones e, incluso, a sus traiciones [Filograsso 2005: 13]. Este en concreto es uno de los más revisitados a lo largo de la historia, y ha traspasado fronteras temáticas, genéricas y de todo tipo [Colomer 2010]. Recordemos que quien primero lo recoge es Perrault, que convierte el relato admonitorio en aviso sexual para doncellas; con los hermanos Grimm pasa a ser una advertencia materna explícita de los peligros del bosque, con mensaje educativo incluido sobre la obediencia. Este último aspecto es especialmente relevante, porque no parece casual que Martín Gaite haya elegido manipular una historia sobre la obediencia para reivindicar un valor contrario: la libertad. Sumándose a la línea feminista que, a partir de los años sesenta, reescribe los cuentos tradicionales para, sin perder la base folclórica, añadir nuevos valores y buscar interpretaciones no patriarcales [Colomer 2010], nuestra autora no solo subvierte el texto en clave posmodernista ${ }^{3}$ [Guerrero 2008], incluyendo en él la reflexión metaliteraria, el hibridismo, la mezcla de realidad y fantasía, la intertextualidad y elementos fuertemente transgresores como la parodia, la ironía o el humor, sino que realiza una neosubversión del mismo, es decir, un trastocamiento temático y formal que rompe con las reglas implícitas a la LIJ tradicional y, más allá de la subversión de los esquemas habituales, no permite el regreso a la realidad de los personajes transgresores. La Alicia de El País de las Maravillas se despierta de su sueño y vuelve a su mundo; la Sara de Caperucita en Manhattan, en cambio, en un capítulo final titulado significativamente "Happy end, pero sin cerrar", comienza un viaje iniciático por el subsuelo de Manhattan que no tendrá vuelta atrás [Guerrero 2008: 42].

En el presente trabajo, por tanto, estudiaremos cómo se subvierten los arquetipos tradicionales -los cuentos infantiles son una fuente inagotable para el estudio de símbolos y arquetipos [Lurie 1990]- y el importante papel que cumple en tal proceso la intertextualidad. Nos fijaremos en la transmodalización genérica -según la terminología de Genette [1982]- con el fin de ver si los elementos estructurales y lingüísticos que sirven para construir tales arquetipos en la novela, se conservan en la adaptación teatral, y cómo llegan al público infantil. Aunque, como sabemos, la obra dramática es a la vez texto literario y espectacular, y no es posible desligar uno del otro [Bobes Naves 2001], aquí nos centraremos en el estudio del texto verbal tratando de no olvidar todos esos elementos -lo que Kowzan [1968] denomina "signos"- que forman parte del aspecto escénico del mismo y que aparecen indicados en acotaciones y didascalias.

Hay que tener presente que los procesos pragmáticos y comunicativos que afectan a novela y teatro son totalmente distintos. Por eso al realizar una versión teatral se producen necesariamente alteraciones cuantitativas y cualitativas. Podemos preguntarnos, en primer lugar, si el texto en estudio posee valores teatrales virtuales que facilitan la transmodalización. Así parece ser, según leemos en una de las cartas (fechada el 7/10/1998) que Stefania Colla manda a Martín Gaite sobre los preparativos de la representación ${ }^{4}$. En ella afirma: "Non voglio dire che sembra scritto per il teatro, perché un libro è un libro (punto e basta!), ma devo dirLe [...] che non è [stato] affatto arduo far indossare a Sara Allen, a Miss Lunatic, a Edgard Wolf e agli altri, i panni di personaggi di un'opera teatrale". Los motivos de tal facilidad, a nuestro entender, son, entre otros, un número no excesivo de escenarios y personajes; una línea argumental muy clara, que sigue el esquema del viaje iniciático; el interés y variedad de una historia que se desarrolla en un espacio temporal reducido; $y$, sin duda, la carga dialogal y la fuerte oralidad de la novela, que facilitan enormemente la transposición. Todo ello unido a la reutilización de un clásico, de sobras conocido y de éxito universal.

Aun con todo, las modificaciones realizadas en el texto original para plegarse a las necesidades teatrales son evidentes. La síntesis u omisión de algunos elementos es señalada en otra carta por Colla que, además de explicar que hay situaciones difícilmente transferibles al teatro, alega que el espectáculo no debe resultar demasiado largo ${ }^{5}$. Explica que, por ello, en algunas ocasiones ha realizado un collage, entremezclando diálogos pertenecientes a diferentes situaciones $y$, sobre todo, ha reducido el número de escenarios y personajes, atribuyendo a algunos las frases correspondientes a otros ${ }^{6}$. Efectivamente, en la obra teatral, que se desarrolla en dos actos-divididos respectivamente en cinco y cuatro escenas- desaparecen seis personajes. Cuatro de ellos -los Taylor, vecinos y amigos de los Allen; el comisario de policía y uno de los chóferes- se diluyen sin dificultad en los parlamentos y la acción de otros personajes. En

Aunque la subversión no es propia solo del posmodernismo: toda la LIJ, al alejarse de los valores convencionales del mundo de los adultos, es siempre subversiva en un grado mayor o menor [Lurie 1990].

4 Todas las cartas de Stefania Colla a Carmen Martín Gaite aquí nombradas han sido consultadas en el archivo del Teatro Colla, que se encuentra en el centro Apice de la Universidad de Milán, y están catalogadas en "Copioni moderni" (1999/8) como "Corrispondenza relativa alla traduzione dell'opera Cappuccetto Rosso a Manhattan in italiano".

5 "Si accorgerà che alcune situazioni sono state omesse e non verranno rappresentate: questo perché difficilmente realizzabili in teatro e perché lo spettacolo non deve risultare troppo lungo". Carta de Stefania Colla a Carmen Martín Gaite (12/01/1999). Archivo "Teatro Colla", Centro Apice (Milán).

6 "Si accorgerà che, talvolta, ho fatto un lavoro di collage riprendendo dialoghi di diverse situazioni e legandoli fra loro, oppure ho attribuito a certi personaggi frasi di altri. Anche questo risponde alle leggi della sceneggiatura teatrale che non sono sempre le stesse della letteratura!". Carta de Stefania Colla a Carmen Martín Gaite (12/01/1999). Archivo “Teatro Colla”, Centro Apice (Milán). 
cambio, la desaparición del Sr. Allen, padre de Sara, y de Aurelio Roncali, el compañero de la abuela, suponen una pérdida mayor ya que, como veremos, ambos contrarrestan de alguna manera el fuerte arquetipo materno: el primero al establecer cierta complicidad con su hija; el segundo, contribuyendo a crear el mundo fantástico y de libertad de Sara. Quedan cinco personajes principales y siete secundarios. Los principales son la madre (Vivian), Sara Allen (Caperucita), Miss Lunatic, la abuela (Rebeca Little) y Mr. Woolf. Los tres primeros, considerados por la compañía Colla los más importantes, con mayores necesidades de interacción y movimiento, son representados por actores reales; en cambio la abuela y Mr. Woolf, que tienen un espacio más definido, están encarnados por marionetas de grandes dimensiones, capaces de moverse en escena al lado de personas de carne y hueso $^{7}$. Los secundarios -el presentador (que no aparece en la novela, y sirve para situar e introducir la acción), Greg Monroe, el Asistente, el Director, Norman, la Camarera y Peter el chófer-, funcionales a la acción, son también marionetas.

Hay muchas situaciones que se omiten en la versión realizada para los escenarios: los viajes de Sara en el metro, la celebración de su cumpleaños en el restaurante chino, así como la conversación de Miss Lunatic con el comisario O'Connor, gracias a la cual conocemos más en profundidad al personaje (su interés por atender a los marginados, sus amistades en el barrio, etc.). La información que aporta esta escena es recogida hábilmente en el coloquio entre Mr. Woolf y Miss Lunatic, que en la novela no se produce. El café cercano a Lincoln Center, donde se rueda una película, es en la versión teatral la propia pastelería de Mr. Woolf, con lo que se evita un escenario más. Tampoco se nos dice que Sara se ha ido a ver a su abuela aprovechando la ausencia de sus padres, que han ido al funeral de su tío, y al final la niña acude a Battery Park en la limusine conducida por Peter, y no en un taxi. Pero coincidimos con Colla en que todos ellos son cambios que no alteran la trama, y que sirven a las necesidades estructurales de la obra. Otras modificaciones, en cambio, se justifican por buscar referentes más conocidos o adecuados para el espectador italiano. Es el caso del Radio City Music Hall, "storica sala di concerti newyorkese" que, como se nos indica en acotación, se ha preferido al New York Theatre Centre del original en cuanto "più famosa e risconoscibile" [MG 1999: 12]". Y este es probablemente el motivo de la sustitución de la canción Parlami d'amore, Mariú por Amado mío, de Rita Hayworth, o de la poesía final, de Pico della Mirandola, por otra de corte más infantil. Pero estos dos últimos casos sí que inciden, aunque levemente y como veremos, en la significación del texto.

Pasemos entonces a ver cuáles son los rasgos estructurales y lingüísticos que definen y delimitan los cinco principales personajes de la novela, y cómo pasan a la versión teatral. Cualquier forma de subversión literaria, afirma Morales Ladrón [2002: 170], parte necesariamente de la recuperación y revisión de paradigmas asentados para poder cuestionarlos y reescribirlos. Empecemos por uno de los mejor definidos: el de la madre.

\section{Los personajes}

\subsection{La madre}

La madre, Vivian -en la obra de teatro simplemente "mamma Allen"-, se coloca en el polo negativo (opuesto al ocupado por Sara, Miss Lunatic y la Abuela, incluso por el Lobo), ya que es la que, con sus prohibiciones, pretende impedir a Sara su sueño de libertad [Cusato 1996]. Coincide con el arquetipo de la madre tradicional, abnegada, constantemente preocupada por el bien familiar y firme protectora de las normas sociales. Presume de su espíritu de sacrificio -su trabajo en una residencia de ancianos, en la cual se considera imprescindible, continúa y corrobora su función familiary se ocupa de detalles prácticos en los que nadie (ni su madre, ni su hija) parece interesarse, respondiendo más a la necesidad de sentirse gratificada que a verdadero amor al prójimo.

Hay varios elementos que caracterizan, a través del habla, al personaje. En la obra teatral se concentran e incluso se intensifican. Esta es la primera intervención de Vivian:

MAMMA: Sara, Sara! Forza, sbrigati! Si può sapere a che cosa stai pensando? Non vedi com'è tardi? Non sembra, ma è un viaggio. Da Brooklyn a Manhattan è un viaggio lungo molte miglia. Torneremo indietro soltanto questa sera [MG 1999: 2].

Desde el principio Vivian tiene un tono incisivo y autoritario. Emplea frases breves y tajantes, numerosos imperativos e interrogativas retóricas con una marcada finalidad reprobatoria. Y, sobre todo, repite continuamente (más que en la novela) una muletilla que, referida al trayecto para ir a ver a la abuela, define al personaje: "Parece que no, pero es un viaje. Un viaje de muchas millas" [MG 2012: 66] $]^{9}$. Además de dar cuenta de su carácter ansioso, se constata la distancia subjetiva que existe entre el universo de la madre y el de la abuela, simbolizada en esos kilómetros que separan Brooklyn de Manhattan, y que en cambio Sara recorrerá alegremente en metro. En la versión teatral tal distancia se refleja a través del telón de fondo del escenario, una gigantografía del puente de Brooklyn, el cual, como se explica en acotación, "é importante nella storia: rappresenta [...] un passaggio, un mezzo verso l'isola fantastica e misteriosa di Manhattan" [MG 1999: 1].

Tal como se explica en la carta de Stefania Colla a Carmen Martín Gaite fechada el 7/10/1998. Archivo "Teatro Colla", Centro Apice (Milán). A partir de ahora, para indicar las páginas de los ejemplos, nos referiremos a las ediciones usadas de la siguiente forma: texto original [Martín Gaite 2012]: MG 2012; traducción italiana [Martín Gaite 1993]: MG 1993; versión teatral [Martín Gaite 1999]: MG 1999.

9 Es interesante constatar que Sara, como se indica en acotación, se burla de esta muletilla: “(Facendo il verso a sua madre)... da Brooklyn a Manhattan è un viaggio lungo molte miglia. Torneremo indietro soltanto questa sera...” [MG 1999: 3]. Se trata de una intensificación de la versión teatral que no aparece en el texto original. 
De la misma manera, la madre viene descrita por su continua obsesión por la meteorología ${ }^{10}$, lo cual no deja de ser un intento de controlar lo incontrolable, y produce un efecto humorístico cimentado en la acumulación de datos y en la hipérbole. Ante la queja de Sara, que ha tenido que ponerse el impermeable rojo aunque no llueva, la madre responde:

MAMMA: Non si sa mai. Anch'io ho preso l'ombrello. Bisogna essere previdenti [...]. Le previsioni hanno detto che la nuvolosità è variabile. Hanno anche detto che si prevede un uragano sulle coste della Florida, nel Minnesota cinque strade municipali sono interrotte, una perturbazione sta avanzando dal centro Europa, a ovest del Mediterraneo [MG 1999: 2] ${ }^{11}$.

Vivian incorpora muchas interjecciones a su lenguaje ("Dio mio", "Santo Cielo") que se concentran en el texto teatral y demuestran su disconfiormidad con aquello que no se adapta a su modelo mental; a la vez, desautoriza lo que dice su hija por medio de breves frases exclamativas: "Che sciocchezze!", "Che assurdità!". Los vocativos con función fática son abundantes -“Sara!", "Mammaaa!"- y buscan llamar la atención de sus interlocutores para que el mensaje impositivo llegue lo mejor posible y sea efectivo.

La mentalidad rígida y tradicional de Vivian se traduce lingüísticamente en otro detalle. Muy consciente de las jerarquías sociales, insiste en llamar de usted a su madre, quien se lamenta del hecho. La obra teatral mantiene el mecanismo intensificándolo de manera muy eficaz, ya que el tratamiento elegido en italiano es la forma arcaica "voi", que solía usarse como modo de respeto con padres y abuelos ${ }^{12}$. Otra nota de humor, que sirve para caracterizar a Vivian, es que ella se justifica invocando una autoridad externa, su padre; autoridad que es automáticamente desautorizada por su propia madre (que lo tacha de anticuado):

NONNA: Non essere noiosa, Vivian. Lascia perdere. E non darmi del voi! Quante volte te lo devo dire! MAMMA: Ci ho già provato, ma non ci riesco. Devo darvi del voi. Il babbo, che riposi in pace, diceva che dare del tu ai genitori era segno di mancanza di rispetto.

NONNA: Ma tu non mi porti nessun rispetto, anche se mi dai del voi! E neanche voglio che me ne porti, sia ben chiaro. E poi, figliola, tuo padre era un po' antiquato [MG 1999: 4] $]^{13}$.

\subsection{Sara}

Caperucita es retratada, igual que en la novela, con los atributos que hacen reconocible al personaje: va vestida con un impermeable rojo y lleva una cesta con la imprescindible tarta para su abuelita. Pero el personaje se muestra en seguida muy diferente al descrito por los hermanos Grimm. En primer lugar, por su rebelión ante la figura materna: en la novela afirma que "no le hacía ninguna ilusión tener hijos para adornarlos con sonajeros, chupetes, baberos y lacitos, que lo que ella quería de mayor era ser actriz y pasarse todo el día tomando ostras con champán" [MG 2012: 39]. Con ello se acerca manifiestamente al arquetipo encarnado por la abuela, muy alejado del de la madre tradicional. De hecho es significativo que, igual que ella, rechace la tarta de fresas, que simboliza el conjunto de los valores patriarcales de la madre [Llorente 2002: 3].

Sara muestra su rebelión con su comportamiento (escapa de su casa, en Brooklyn, para ir a ver a su abuela a Manhattan, en un viaje iniciático en el que conocerá a Miss Lunatic y a Mr. Woolf), pero también con su lenguaje, ya que usa el nonsense, frecuente en los cuentos infantiles para caracterizar el habla de los niños. Sara confiesa, ante el estupor de la madre, que inventa palabras - "farfanías"- que no significan nada, pero tienen un sonido divertido -"amelva", "tarindo", "maldor", y sobre todo "miranfú", que tendrá el poder mágico de abrir la puerta que conduce a la libertad-. Además de ser un lenguaje no convencional, por tanto inaceptable en el mundo fuertemente reglado de la madre, este es portador de un orden simbólico, presemiótico y materno [Kristeva 1974], alejado de lo patriarcal -que en este caso, paradójicamente, es representado por la madre-, en el cual Sara se encuentra absolutamente libre. El episodio pasa, aunque de forma algo más breve, a la obra teatral. Un signo paralingüístico en didascalia -"(Nel frattempo Sara si è messa a parlare sottovoce, fra sé e sé, ridendo)"- y la indignada réplica de la madre -"Ma... perché stai ridendo? Perché muovi le labbra?" [MG 1999: 2-3]-, demuestran que esta última es ajena al universo de su hija. El nonsense se transfiere sin grandes modificaciones (solo una palabra se italianiza con la -e final: "maldore"):

MAMMA: Che cos'è che inventi?

SARA: "Farfanie". Parole che nascono senza volerlo, come i fiori selvatici che non c'è bisogno di innaffiare. Mi vengono per caso, a mo' di scioglilingua, mescolando vocali e consonanti a casaccio.

MAMMA: E che cosa vogliono dire?

\footnotetext{
10 "De frío, de calor y de tormentas lo sabía todo, y es de lo que hablaba siempre por las mañanas con los viejos aquellos que, según decía suspirando, la querían más que su propia madre. Se oía todos los partes metereológicos de la televisión y los comentaba con ellos” [MG 2012: 71].

11 La versión teatral traduce de forma muy literal el original: "Nunca se sabe -contestaba la señora Allen-. Yo también llevo el paraguas, ¿ves?, hay que ser precavidos [...]. El hombre del tiempo ha dicho que la nubosidad es variable. Ha dicho también que se anuncia un huracán por las costas de Florida, que en Minnesota hay cinco carreteras vecinales interceptadas, que el anticiclón se incrementa en el centro de Europa y tercio oeste del Mediterráneo y que..." [MG 2012: 70].

12 Hoy en desuso y presente solo en algunas hablas dialectales meridionales, el "voi" era manifestación de disimetría a nivel anagráfico, social, de sexo o situación emotiva [Dardano y Trifone 2002].

13 "-No seas pesada. Vivian, vamos a dejar eso. ¡Y no me llames de usted! ¡Mira que te lo tengo dicho veces!

-Ya lo he intentado, pero no me acostumbro. Me sale el usted. Papá, que en paz descanse, decía que tratar a los padres de tú era una falta de respeto. -¡Pero si tú a mí no me tienes ningún respeto, aunque me trates de usted! Ni quiero que me lo tengas, por supuesto. Además, hija, tu padre era un antiguo" [MG 2012: 80].
} 
SARA: Niente. Di solito non vogliono dire niente, come "amelva", "tarindo", "maldore". Ma qualche volta sì. Ad esempio "miranfü". Vuol dire "adesso succederà qualcosa di nuovo" oppure "ci sarà una sorpresa per me" [MG 1999: 3]

Pero la rebelión de Sara se muestra sobre todo a través de la subversión de los modelos literarios tradicionales. El primero es, evidentemente, el propio cuento de Caperucita, cuyos personajes arquetípicos y desenlace -hasta el mismo título- aparecen tergiversados. Este es el retrato que Sara hace del Lobo en la versión teatral, traduciendo casi literalmente el original ${ }^{14}$ :

Ad esempio, prendiamo la favola di Cappuccetto Rosso: il lupo ha una faccia così buona e assetata d'affetto che Cappuccetto Rosso deve fidarsi di lui. Anch'io mi fido di lui, non mi fa paura per niente. E' impossibile che un animale così simpatico possa mangiare qualcuno [MG 1999: 5].

A ello se suman las continuas referencias, diseminadas en la novela, a otros relatos, como Alicia en el País de las Maravillas o Robinson Crusoe. De ellos se nos dice que lo principal es que los protagonistas iban ellos solos por el mundo, "libres". Y, sobre todo, que sus finales están equivocados. La versión teatral no pierde tal información y resume la intervención de Sara en las siguientes palabras, apoyadas eficazmente en una didascalia:

Interviene infervorata su di un argomento che le sta molto a cuore) I finali, mamma, sono tutti sbagliati! [...]. E anche il finale di Alice, quando dice che è stato tutto un sogno. Perché mai deve dire così? E neppure Robinson Crusoe deve ritornare nel mondo civile, se sta così bene sull'isola! [MG 1999: 5].

Aunque por necesidades de síntesis se le dedique menos espacio, es el suficiente para que el espectador entienda no solo que Sara tiene una imaginación portentosa, capaz de cambiar el final a los cuentos de todos conocidos, sino también que cambiándolos logra subvertir el orden establecido, y que ello puede pasar del terreno de la fantasía al de la vida real, preludio de lo que sucederá al final ${ }^{15}$.

\subsection{La abuela}

En la obra teatral no se dice cómo se llama (Rebeca), sabemos solo su nombre artístico: Gloria Star, probable alusión a la hollywoodiense Gloria Swanson, que se cita en el texto original. El hecho es importante porque este, junto con el de Sara, evoca personajes bíblicos estériles, es decir, que no son madres [Fabiani 2011: 110]. Del mismo modo, el abuelo de Sara se llamaba Isaac, otro nombre bíblico que representa la autoridad patriarcal -muy bien interiorizada por la hija, como hemos visto en un ejemplo precedente-. Todos ellos (Sara, Rebeca e Isaac) contrastan con el de la madre, Vivian, que queda desautorizada al no poseer ningún vínculo bíblico.

La abuela es caracterizada inmediatamente a través de la acotación que da inicio a la segunda escena. Se nos dice que su casa está desordenada: "ci sono una vecchia poltrona sfondata, giornali sparsi qua e là, indumenti d'ogni genere, lettere, fotografie, oggetti ovunque". Y ella se presenta "fuma[ndo] una sigaretta senza filtro o con un lungo bocchino" [MG 1999: 3-4]. Dicho desorden, sin embargo, es visto de manera positiva porque significa creatividad y fantasía, valores opuestos a los de Vivian. Es imposible reconocer en esta otra madre el arquetipo materno: no es servicial, no sigue las normas establecidas y rechaza los cuidados de su familia. Es decir: no tiene nada que ver con la abuelita del cuento tradicional.

Son significativos sus gustos culinarios, alejados de los alimentos nutritivos que seguramente elegiría su hija. Su lista de la compra está compuesta de "liquore alla pera, sigarette senza filtro, pop corn, burro di noccioline, ketchup, una confezione di hamburgers surgelati e patatine fritte" [MG 1999: 7]. Declara no hacer las típicas tareas del ama de casa, como cocinar, no porque no sepa, sino porque es aburrido, y desmitifica la tarta de fresas que recibe de su hija, que nunca come sino que regala a algún pobre. Y juega al bingo. Tiene un pasado poco tradicional: era una cantante guapa y seductora, pelirroja de ojos verdes, que solía vestir también de verde, detalle al que se alude numerosas veces tanto en el original como en la obra teatra ${ }^{16}$. Su poder de seducción se simboliza en una referencia intertextual, una vieja canción italiana de los años treinta, Parlami d'amore, Mariú, interpretada por Vittorio de Sica. La referencia se sustituye en la versión teatral por Amado mío, de Rita Hayworth. Ello probablemente obedece a que esta última es más conocida y da un tono hollywoodiense a la escena. Pero así cambia no solo el tema -ya que Mariú habla de la ilusión de un amor- sino también el sujeto: en la primera canción el hombre canta a su amada; en la segunda canta la amada misma, lo cual concede mayor poder actorial al personaje femenino.

El carácter poco tradicional de la abuela no es visto con buenos ojos por la familia: su yerno la define con el

\footnotetext{
14 "En aquel dibujo, el lobo tenía una cara tan buena, tan de estar pidiendo cariño, que Caperucita, claro, le contestaba fiándose de él, con una sonrisa encantadora. Sara también se fiaba de él, no le daba ningún miedo, era imposible que un animal tan simpático se pudiera comer a nadie" [MG 2012: 45].

15 Hay otras referencias intertextuales en la novela que, en la misma línea, constituyen una pista interpretativa del texto. La primera parte, que se titula significativamente "Sueños de libertad", comienza con una cita de Celia en el colegio, de Elena Fortún. Es sabida la admiración de Martín Gaite por la escritora madrileña, cuyo personaje principal, Celia, es prototipo de la niña independiente y curiosa, siempre dispuesta a "desmontar los tópicos con que acorralan al niño las personas mayores" [Martín Gaite 2002a: 82]. Todo ello no aparece en la versión teatral. Para otras referencias intertextuales vid. Cusato [1996], Fabiani [2012] y Blejer [2007].

16 Sara dice de su abuela que "le había parecido más joven que su madre. Llevaba puesto un traje de seda verde y estaba sentada ante un tocador" [MG 2012: 52]. Y Mr. Woolf describe así a Gloria Star, el día que la conoció y se enamoró de ella: "Y le había sonreído dos veces mientras la cantaba [...]. Después se habían mirado. Los ojos verdes de ella lo taladraban serios y risueños al mismo tiempo. El vestido que llevaba también era verde" [MG 2012: 200].
} 
apelativo "lagarta" [MG 2012: 41]. Traducido en la novela con el demasiado literal "lucertola" o "lucertolona", pierde la connotación que tiene en femenino, inexistente en el masculino "lagarto", y que, aplicada a una mujer, la caracteriza genéricamente de forma negativa ${ }^{17}$. El término desaparece en la versión teatral.

Sus frases son breves, sobre todo cuando habla con su hija. Para responderle usa estructuras negativas -"mai", "neanche a parlarne", "non essere noiosa"- y esgrime a menudo el arma de la ironía. Por ejemplo, ante la pregunta "Chissà quando metterete la testa a posto?", ella responde "Mettere la testa a posto deve essere noiosissimo"; o "Non si è mai vista una perdita di tempo più grande" (referido al hecho de dormir) [MG 1999: 4]. Cuando Vivian se queja de que Sara hace preguntas "inconvenientes", la abuela afirma: "Mandala da me, che io sullo sposarsi e sulla libertà posso insegnarle un certo numero di cose" [MG 1999: 5]. Si bien es verdad que los ejemplos de ironía en la novela son más numerosos, la versión teatral usa los mismos mecanismos.

La abuela sirve además para introducir a un personaje al cual se le concede bastante peso en la novela -aunque solo aparece evocado por Sara- y que, por desgracia, desaparece en la obra teatral. Se trata de su ex-pareja, Aurelio Roncali, de origen italiano, cuyo nombre bien podría ser un velado homenaje de Martín Gaite al admirado Gianni Rodari. Muy mal visto por Vivian -que se apresura a aclarar a la niña que no es su abuelo, ya que abuelo solo hay uno, Isaac-, es propietario de una librería e inicia a Sara en la lectura de cuentos fantásticos al regalarle sus primeros relatos que, "casualmente", serán los ya nombrados Caperucita, Robinson Crusoe y Alicia en el País de las Maravillas. Le hace otros dos regalos fundamentales: el primero, un rompecabezas de letras con el que Sara comienza a apoderarse de lo que Kristeva [1974] llama el orden semiótico. En ese momento el niño abandona el orden presemiótico o simbólico, donde reina el subconsciente y la presencia materna, para pasar al orden representado por el padre, y con ello a un universo reglado y patriarcal. Gracias al rompecabezas, Sara va entrando en el orden semiótico de forma no traumática, jugando con las letras, igual que juega con las "farfanías":

[...] les tomó cariño, incluso antes de entender para qué servían. Ponía en fila los cubos, les daba la vuelta y combinaba a su capricho las letras que iba distinguiendo unas de otras por aquellos perfiles tan divertidos y peculiares. La E parecía un peine, la $\mathrm{S}$ una serpiente, la $\mathrm{O}$ un huevo, la $\mathrm{X}$ una cruz ladeada, la $\mathrm{H}$ una escalera para enanos, la $\mathrm{T}$ una antena de televisión, la F una bandera rota [MG 2012: 53].
El segundo regalo es un plano de Manhattan que siempre llevará consigo para orientarse por la isla, puerta de su libertad, y que en la versión teatral no desaparece, aunque no se hable de su procedencia. Con estos dones Roncali se muestra colaborador del padre -personaje que tampoco se incluye en la versión teatral, y que a su vez regala a Sara un cuaderno para escribir, en el que empezará a pintar "unos garabatos que imitaban las letras y otros que imitaban muebles, cacharros de cocina, nubes o tejados. No veía diferencia entre dibujar y escribir" [MG 2012: 54]- en el abandono progresivo por parte de Sara del orden simbólico para ir entrando en la edad adulta.

\subsection{Miss Lunatic}

Es el personaje más misterioso del relato, el espíritu de la libertad que vive dentro de la estatua neoyorquina y de noche sale a pasear por la ciudad. Tendrá para Sara la función de guía en sustitución y oposición a la figura materna. Se presenta de forma anticonvencional: una vieja de largos cabellos blancos y vestidos extraños que empuja un anticuado cochecito de niños, como un clochard. La detallada descripción del personaje, en acotación $^{18}$, es exactamente igual a la de la novela, en traducción de Finassi Parolo: el marcado tono literario de la misma y el uso de los verbos en pasado así lo demuestran.

Dos elementos intertextuales de la novela nos ayudan a interpretar quién es Miss Lunatic. El primero es una referencia a La Celestina que abre como cita introductoria la segunda parte del relato y reza: "A quien dices tu secreto, das tu libertad". Esta se repite en el interior del texto, incorporada a un diálogo, y así es conservada en la versión teatral: "A chi dici il tuo segreto, dai la tua libertà" [MG 1999: 17]. Se pierde en cambio otra referencia fundamental a Italo Calvino y su Caballero Inexistente. En la novela el Comisario O'Connor (personaje que, como dijimos, no pasa al teatro) le pregunta a Miss Lunatic cómo sale adelante. Ella contesta: "Echándole fuerza de voluntad, señor, para decirlo con palabras de El Caballero Inexistente" [MG 2012: 118]. En la versión teatral esta conversación confluye casi por completo en el breve diálogo entre Mister Woolf y Miss Lunatic, pero la referencia desaparece. El guiño de Martín Gaite es evidente, ya que Agilulfo y Miss Lunatic no existen como tales, sino que viven en el interior de una armadura, el primero; en la Estatua de la Libertad, la segunda.

Aunque su lenguaje está plagado de coloquialidad y de elementos fraseológicos, como el de la abuela, su discurso es menos irónico y mucho más asertivo. Ello tiene que ver con el papel que se le ha asignado, el de guía

17 Es verdad que una traducción no literal habría llevado a otro tipo de problemas, ya que en una ocasión Sara, que desconoce las connotaciones genéricas del término, asocia este al vestido verde que su abuela solía usar de joven: "cuando su padre llamaba lagarta a la abuela, Sara pensaba que es que la recordaría, como ella, vestida de verde" [MG 2012: 53]. El uso de un equivalente ("una che la sa lunga", por ejemplo) habría impedido el juego asociativo, pero la traducción italiana no permite descodificar la connotación: "quando suo padre chiamava la nonna lucertolona, Sara pensava che la ricordasse, come lei, vestita di verde" [MG 1993: 23].

18 "É una donna molto vecchia, vestita di stracci con in testa un cappello a larghe teste che le copriva quasi interamente il volto. La chioma folta e bianca come la neve le scendeva lungo la schiena, certe volte svolazzando nel vento, altre invece raccolta in una spessa treccia che le arrivava sino alla vita. Trascinava una carrozzina vuota. Era un modello vecchissimo, piuttosto grande, le ruote molto alte e la cappotta alquanto consunta" [MG 1999: 8]. 
de Sara, solo que al contrario que las de la madre, sus recriminaciones son adecuadas y colaborativas. Además y a diferencia de esta, es capaz de afecto físico - abraza a la niña, la acaricia, la lleva de la mano-y usa numerosos apelativos como "guapa", "bonita" o "hija mía”, que en la obra se traducen con equivalentes funcionales: "piccola", "cara", etc. El lenguaje de Miss Lunatic pasa casi intacto a la obra teatral ${ }^{19}$ :

MISS LUNATIC: Vieni Sara [...]. Cammina più in fretta, vai a passo di lumaca. Un-due, un-due, proviamo a camminare insieme [MG 1999: 11].

Siempre en relación con su papel de guía, su discurso está plagado de frases sentenciosas que denotan su sabiduría y que, aunque en menor número, se conservan en la versión teatral: "A volte le domande contengono già la risposta" [MG 1999: 12]; "Non bisogna mai dare retta ai divieti" o "L'ignoranza non conosce confini" [MG 1999: 13]. También en ocasiones usa la ironía. Por ejemplo, cuando Sara le dice que no le confiaría su secreto ni siquiera a un futuro novio, Lunatic, afirma "men che meno a un fidanzato, Sara; per carità, gli uomini hanno la lingua lunga" [MG 1999: 17] $]^{20}$. Del mismo modo, se muestra firme para defender sus derechos. Con el Asistente, que no le quiere dejar entrar en una cafetería porque están rodando una película, usa frases interjectivas como "¿Pero se pueden ir todos ustedes al diablo y dejarnos en paz? Vamos, Sara, salgamos de aquí. Nos tienen cercadas" [MG 2012: 162], que pasa al italiano con cierto grado de intensificación: "(Alzandosi infuriata) Ma che accidenti vi prende? Volete andarvene tutti al diavolo e lasciarci in pace? Insomma... [...] toglietevi di mezzo...!" [MG 1999: 15]. Su actitud da resultado ya que consigue que Sara, que al principio se siente perdida en Manhattan, deje de llorar -"Dai, piccola, non piangere un'altra volta, stà a vedere che mi è toccata un'amica pappa molle" [MG 1999: 11] ${ }^{21}-\mathrm{y}$ aprenda a imponerse para defender lo que quiere- por ejemplo con el chófer, que no la quiere llevar a su destino: "Allora che cosa? Voglio andare a Battery Park, punto e basta" [MG 1999: 24]. El viaje iniciático hacia la independencia culminará cuando, a través del túnel que se abre gracias a la moneda mágica que Miss Lunatic le ha dado, y pronunciando una de sus "farfanías" como palabra mágica, Sara desaparezca en el interior de la Estatua de la Libertad.

\subsection{Mr Woolf}

Los roles masculinos activos -el cazador como salvador; el lobo como agresor o peligro externo ${ }^{22}$ - se reducen a uno solo en la obra de Gaite. El lobo funciona como un icono del cual conserva solo el nombre, Edgard
Woolf. Millonario hombre de negocios de Manhattan, es el dueño de la pastelería "Sweet Woolf”, dulce lobo, famosa por su tarta de fresas. Por lo demás, alejado por completo del modelo tradicional, Mr. Woolf se nos presenta como un personaje triste, inseguro, solo, digno de ternura. En espera de un amor que nunca ha llegado y preocupado por el descenso de calidad de sus tartas de fresa: "mi sento un fallito" [MG 1999: 7], asegura.

Aun así, Mr. Woolf conserva algunos de los atributos del Lobo. Encuentra a Sara en un "bosque" (Central Park) de noche; posee una actitud "animal", que se acentúa en la acotación -"le narici del suo naso affilato si dilatavano come se stessero annusando qualcosa, il che gli dava un'aria da animale in agguato" [MG 1999: $19]^{23}$ - y le hace la pregunta reglamentaria: “¿Qué haces aquí tan sola, hermosa niña? ¿Esperabas a alguien?" [MG 2012: 185], la cual pasa literalmente al italiano: "Che cosa fai qui tutta sola, bella bambina? Aspetti qualcuno?" [MG 1999: 19]. Además, se respeta a rajatabla la cuestión de la elección de caminos para ir a casa de la Abuela. En este caso es la propia Sara la que desea darse un paseo por Manhattan en una limusine de Mr. Woolf, lo cual permitirá que este llegue antes; solo que la ventaja temporal es aprovechada por él para conquistar a Rebeca, de quien se había enamorado cuando era joven. El Lobo, pues, no está interesado en Caperucita, como en el cuento, sino en la abuela y en su tarta de fresas, y con su visita resolverá dos problemas a la vez: la falta de amor y sus dificultades laborales. Los papeles, decididamente, se tergiversan: el Lobo no se come a la abuela, ni a la niña, y no hay ningún cazador o figura paterna que salve a Caperucita. Es más: Mr. Woolf es capaz de llorar y de despertar piedad en Sara, quien "sin darse cuenta, empezó a acariciarle el pelo como a un niño. Lo tenía muy limpio, suave al tacto y emitía en la penumbra unos reflejos cobrizos muy peculiares" [MG 2012: 188]. La escena pasa al texto italiano en acotación: "Sara cominciò ad accarezzargli i capelli, come a un bambino" [MG 1999: 20]. Mr. Woolf, como Miss Lunatic, sabe acercarse afectiva y físicamente a la niña, afecto al que Sara corresponde. En otra acotación leemos: "Sara, con uno slancio spontaneo, abbracciò Mister Woolf, che era sempre seduto sulla panchina e gli stampò un bacio in fronte" [MG 1999: 21] $]^{24}$. Además, Sara pasa rápidamente a tutearle (tuteo que exige a también Peter, el chófer, rechazando el título de "señorita"), en claro contraste con el usted usado por su madre.

\section{Conclusiones}

El análisis comparativo entre la novela y la versión teatral de Caperucita en Manhattan nos ha llevado a ver las

\footnotetext{
"Vamos Sara, hija, anda más ligera, que vas a paso de tortuga [...]. A ver si acompasamos la marcha, un-dos-un-dos...” [MG 2012:148].

"A un novio menos que a nadie, por Dios, hija, los hombres se van mucho de la lengua" [MG 2012: 172].

"Vamos, hija, no llores otra vez [...]. A ver si me has salido una amiga de merengue" [MG 2012: 147].

El único peligro del que se nos habla en el cuento es "el vampiro del Bronx", misterioso bandido que, según cuenta la leyenda, sale de noche en el parque cercano a donde vive la abuela. El resultado "subvertido" [Morales Ladrón 2002] es que este parque es el más seguro de Nueva York, ya que por miedo al supuesto bandido, no va nadie.

23 En el original se nos dan menos "pistas". Se nos dice que Woolf "hacía acercado la cesta a su rostro afilado, rodeado de un pelo rojizo que le asomaba por debajo del sombrero, estaba oliendo la tarta y sus ojos brillaban con triunfal codicia” [MG 2012: 185].

24 "En un arranque espontáneo, abrazó a mister Woolf, que seguía sentado en el banco y le estampó un beso en la frente. Él se puso un poco colorado" [MG 2012: 192].
} 
obvias diferencias existentes entre ambas. Los cambios más significativos tienen que ver con la inevitable labor de síntesis que reduce personajes y escenas. Concretamente desaparecen dos personajes importantes, Aurelio Roncali y el padre de Sara, que en la novela contrarrestan el arquetipo materno y contribuyen a que Sara sea libre. Pero a pesar de las reducciones, la obra teatral sabe compensar las pérdidas a través de ciertos rasgos que se concentran e intensifican, como la "muletilla" que repite la Sra. Allen, y a través sobre todo del uso de didascalias $\mathrm{y}$ acotaciones que, por medio de diversos signos (notas sobre el vestuario, detalladas descripciones de los personajes y los escenarios - tomados a veces de la traducción de la novela, que de esta manera se pone al servicio de la representación escénica -, indicaciones paralingüísticas), así como de una serie de gigantografías que enmarcan y valorizan cada escena, consiguen dar una correcta significación de las mismas.

Hemos observado también cómo los arquetipos del cuento original se subvierten en nuestra Caperucita, creando nuevas genealogías femeninas que rompen con el sistema patriarcal [Fabiani 2011] ${ }^{25}$, y el importante papel que cumplen en ello las diferentes referencias in- tertextuales. Estas, si bien son inferiores en número con respecto al texto original, son suficientes como para no desvirtuar en absoluto el mensaje y la esencia del cuento mismo. Y es que Carmen Martín Gaite ha querido con él hacer un homenaje a la libertad -“Todo tenía que ver con la libertad" [MG 2012: 45]-, la cual se anuncia no solo en la ruptura de dichos arquetipos, sino también en el rechazo mismo de la ejemplaridad del cuento tradicional, ligada a la obediencia de la niña y por tanto a la falta de libertad del personaje protagonista. Caperucita, en cambio, quiere ser libre y, cambiando el final de su cuento -al igual que los de Alicia o Robinson Crusoe-, encuentra su propio camino perdiéndose en los entresijos de la estatua neoyorquesa.

Quizá la clave interpretativa del texto esté en la poesía final, de Pico della Mirandola, que en la versión teatral ha sido sintetizada en una de tono más infantil que habla, igualmente, de libertad ${ }^{26}$. Al leer esta emotiva reflexión sobre el libre albedrío, no podemos evitar pensar en el triste destino de la hija de Carmen Martín Gaite: "No te hice ni celestial ni terrenal/ ni mortal ni inmortal, con el fin de/ que fueras libre y soberano artífice/ de ti mismo, de acuerdo con tu designio" [MG 2012: 226].

\section{Referencias bibliográficas}

Blejer Eder, Daniella Bettina (2007): "De la madriguera a la libertad. Intertextualidad como subversión en Caperucita en Manhattan", Anuario de investigación en literatura infntil y juvenil, 5: 9-23.

Bobes Naves, Maria del Carmen (2001): Semiótica de la escena. Análisis comparativo de los espacios dramáticos en el teatro europeo, Madrid, Arco Libros.

Calceglia, Ivana (2019): “Continuità e discontinuità nel canone letterario infantile. Il caso di Caperucita Roja”, en Veronica Orazi (et al.) (eds.), Trayectorias literarias hispánicas: tradición, innovación y nuevos paradigmas, Roma, Aispi: 231-242.

Calvi, Maria Vittoria (1998): "La recepción italiana de Carmen Martín Gaite”, Espéculo. Revista de Estudios Literarios (marzo),

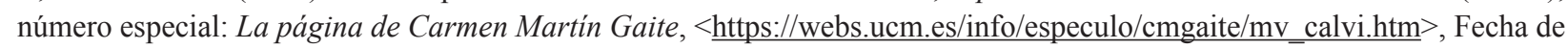
consulta: 10/XII/2019.

- (1999): "La recepción italiana de Carmen Martín Gaite (II)”, Espéculo. Revista de Estudios Literarios (julio), < $<$ https://webs. ucm.es/info/especulo/cmgaite/mvcalvi2.html>, Fecha de consulta: 10/XII/2019.

Colomer, Teresa (2010): Introducción a la literatura infantil y juvenil actual, Madrid, Síntesis.

Cusato, Domenico Antonio (1996): "Su alcune fonti di Caperucita en Manhattan, de Carmen Martín Gaite", en Emilia Perassi (ed.), Tradizione, innovazione, modelli. Scrittura femminile del mondo iberico e americano, Roma, Bulzoni: 481-500.

Dardano, Maurizio y Pietro Trifone (2002): La nuova grammatica della lingua italiana, Bologna, Zanichelli.

Fabiani, Anita (2011): "Dalla fiaba al romanzo: nuove genealogie femminili en Caperucita en Manhattan, de Carmen Martín Gaite”, en Eliana Creazzo (et al.) (eds.), Racconto senza fine, Soveria Mannelli, Rubbettino: 99-112.

- (2012): "Funzioni metanarrative dell'intertesto in Caperucita en Manhattan di Carmen Martín Gaite", en Alessandro Cassol (et al.) (eds.), Metalinguaggi e metatesti. Lingua, Letteratura e Traduzione, Roma, Aispi: 1-16.

Filograsso, Ilaria (2005): Polisemia della fiaba, Roma, Anicia.

Genette, Gérard (1982): Palimpsestes, Paris, Seuil.

Guerrero, Laura (2008): "La neo-subversión en la literatura infantil y juvenil, ecos de la posmodernidad", Ocnos. Revista de estudios sobre lectura, 4: 35-56.

Kowzan, Tadeusz (1968): "Le signe au theatre. Introduction ala semiologie de I'art du spectacle”, Diogene, 61: 59-90.

Kristeva, Julia (1974): La Révolution du langage poétique, Paris, Seuil.

\footnotetext{
25 Hay que decir que no todos ven en el final del cuento tal ruptura con lo patriarcal [Morales Ladrón 2002], ya que al fin y al cabo la Abuelita encuentra su "príncipe azul". Es decir, el personaje femenino se redime, como en la cuentística tradicional, a través del personaje masculino que lo salva. Nosotros creemos que, a pesar de ello, la decisiva subversión de los arquetipos y la apertura final - en un capítulo que se llama "Happy end pero abierto" - del personaje de Caperucita a su propio destino, son lo suficientemente significativos como para considerar este texto como un relato de ruptura.

26 Esta es la poesía que aparece en la versión teatral: "Con il cappuccio rosso ed il cestino in mano/ attraversasti un giorno un ponte americano/ per conquistare infine la meta tanto amata/ per scegliere da sola la libertà sognata" [MG 1999: 24]. Los motivos que se alegan para el cambio son los siguientes: "Si tratta di un passo molto suggestivo ma un po' difficile da comprendere se recitato: stiamo pensando di inserire al suo posto una breve poesia che si rifaccia comunque, con toni più infantili, al senso espresso dal testo originale. Tral'altro, è consuetudine degli ultimi nostri spettacoli, concludere con una filastrocca recitata solitamente dall'attrice protagonista". Carta de Stefania Colla a Carmen Martín Gaite (10/02/1999). Archivo "Teatro Colla", Centro Apice (Milán).
} 
Lurie, Alison (1990): Don't Tell the Grown-ups: Subversive Children's Literature, London, Bloomsbury.

Llorente, Lucía I. (2002): "Caperucita en Manhattan: Caperucita en el país de las maravillas”, Espéculo. Revista de Estudios Literarios, 22, <https://webs.ucm.es/info/especulo/numero22/caperuci.htm>, Fecha de consulta: 10/XII/2019.

Martín Gaite, Carmen (1993): Cappuccetto Rosso a Manhattan, trad. Michela Finassi Parolo, Milano, Salani.

- (1999): Cappuccetto Rosso a Manhattan (versión teatral). Inédito.

- (2002a): Pido la palabra, Barcelona, Anagrama.

- (2002b): Cuadernos de todo, Barcelona, Debate.

- (2012): Caperucita en Manhattan, Madrid, Siruela.

Morales Ladrón, Marisol (2002): “Caperucita reescrita: The Bloody Chamber, de Ángela Carter, y Caperucita en Manhattan, de Carmen Martín Gaite”, Revista Canaria de Estudios Ingleses, 45 (noviembre): 169-183. 